tion of iron, manganese, phosphorus and magnesium, and flame-spectrophotometric analysis of calcium and potassium. The term humus was used for the Ao horizon, as in any study dealing with forest soil profiles.

Before starting the physico-chemical analysis of the Ao horizon, a study was made of the water-retaining capacity of samples collected in cut-over and in neighboring uncut stands by the centrifuge method. No significant difference was obtained. The seed supply from neighboring stands was found to be abundant, and many seeds were detected in the humus layer.

Thus it appears that factors other than the usual explanation for failure of black spruce reproduction in these stands must be looked for. It should also be noticed that other plants associated with black spruce stands, such as Cornus canadensis, Clintonia borealis or Vaccinium canadense, etc, find enough humidity to germinate and develop normally in these sites, while black spruce seed hardly succeeds.

Without assuming that the problem has been completely solved, we think that interesting trends have been found and that experiments in the field are indicated to complete our knowledge of this question.

The statistical analysis of the data is correct. It was made according to the theory of the "pooled standard deviation" (see Snedecor Statistical Methods, 4th ed., pp. $76-77$ and 78 for the theory, and page 65 for probability table). The computations have oeen reviewed and the interpretation has been made according to that theory. No doubt that this part of Snedecor's well known text was overlooked when the appreciation of the statistical analysis was made by Messrs. Haddock and Smith.

Henri LeBlanc

\title{
The Commonwealth Forestry Bureau An Information Centre
}

The following report is intended to bring to the attention of foresters in this country an organization that has been established for our use and should be better known than it is, particularly among research workers. I refer to the Commonwealth Forestry Bureau which is one of the group known collectively as the Commonwealth Agricultural Bureaux. There are two reasons for discussing this matter at the present time: first, it is fresh in my mind, as during the past summer I was a member of the Canadian delegation attending a conference in Great Britain that had as its objective a review of the work of the C.A.B. organization; second, and more significant, is the fact that research activities in the fields of forestry and forest products are increasing rapidly in this country, and for this work to be most efficient, full use should be made of the services provided by the Forestry Bureau.

The rapid growth that has taken place in all phases of scientific research in recent years and the associated flood of scientific literature-far more in any one field than can possibly be dealt with directly by the individual worker-has emphasized the importance of authoritative documentation centres that will survey, index, abstract, and review the world literature in each branch of science and thus keep the scientists in that field informed of developments with as little time-lag as possible. 


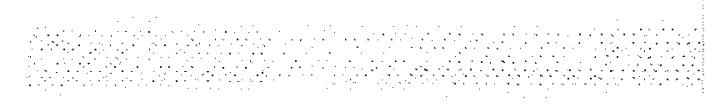

The immensity of this problem with respect to the biological sciences has been indicated by a survey of the abstracting services in this field made recently in the United States. In a preliminary report on this survey (4) it is noted that the total of biological journals published in the world today (includ-

ing those in the medical and agricultural fields) probably exceeds 21,000.

A number of organizations have been set up in different countries to provide the documentation and abstracting services required. Of these, the one that should be of particular interest to us is the Forestry Bureau to which reference has already been made; this is a unit of the Commonwealth Agricultural Bureaux organization that was formed in 1929 on the recommendation of the Imperial Agricultural Research Committee (1927), and with the approval of member governments, for the purpose of providing a joint co-operative information service for agricultural, forestry, and associated sciences in the Commonwealth. The organization consists of 13 units, 12 located in the United Kingdom and 1 in Canada, which in addition to the Forestry Bureau include the Institutes of Entomology, Mycology, and Biological Control (at Ottawa), and the Bureaux of Animal Nutrition, Animal Genetics, Animal Health, Dairy Science, Helminthology, Plant Breeding and Genetics, Pastures and Field Crops, Horticulture and Plantation Crops, and Soil Science. Each bureau is located at a research institute that specializes in its own branch of science, so that the bureau staff may work in close association with those engaged on research in their particular field. Thus, for example, the Commonwealth Forestry Bureau is located at the Forestry School in Oxford, and the Bureau of Soil Science at the Rothamsted Experiment Station.

The main purpose of the Bureaux, as laid down in the original recommendation calling for their establishment, is to collect, collate, and disseminate information on research, each in its own branch of science, and generally to assist research workers in the Commonwealth with information relevant to their subjects. The principal method of doing this is through the publication of abstracts supplemented by review articles, bibliographies and indexes, which together provide for the research worker the contact he requires in his own special field. Basically this organization and the services it provides are paid for through contributions made on a pro rata basis by the governments of Commonwealth countries and the republics of Ireland, India, and Pakistan; the Canadian contribution for all units other than the Forestry Bureau is paid through the Federal Department of Agriculture, while that for the Forestry Bureau is included in the annual budget of the Forestry Branch of the Department of Northern Affairs and National Resources.

While contributing countries receive a quota of the C.A.B. publications free of charge, mainly for distribution among government research units, there is also a considerable demand for these publications on the basis of subscriptions; these have increased considerably in recent years and are by no means confined to Commonwealth countries, but originate wherever there is an active interest in forestry and agricultural research. No less than 58 foreign countries are now taking Forestry Abstracts.

In its report of 1933 the Imperial Committee on Economic Consultation 
and Co-operation ${ }^{1}$ set down certain general principles to be observed in connection with the organization of Commonwealth agencies such as the C.A.B. Among these were "the constitutional equality of participating governments in the appointment of the authority administering the work (an executive committee in the case of the C.A.B.); the provision of adequate finance for a definite period of years; careful and periodical examination of the work and organization of the agency at Commonwealth conferences; and the responsibility of the administering authority to all participating governments." These principles have been closely adhered to throughout; thus since 1929, when the C.A.B. was first established, four conferences have been held in Great Britain, at which the work of the organization has been reviewed and recommendations made in connection with the program in the years to follow-usually for a five-year period. The most recent of these review conferences was held during the summer of 1955 , when representatives of contributing countries spent some five weeks in visiting the Institutes and Bureaux and discussing in detail their objectives, activities and financing. A report of this conference will be available shortly.

So much for the background. What of the services provided by the Commonwealth Forestry Bureau itself and the extent to which these are being used in Canada? The primary function of this Bureau is undoubtedly the preparation and publication of Forestry Abstracts, which is issued quarterly and includes in the most recent volume nearly 4,900 notices of articles in over 550 journals on forestry and related subjects, as well as from innumerable reports, bulletins, and other non-periodical literature, published in over 30 languages. At the present time the coverage of the relevant world literature is considered to be fairly satisfactory; although there are arrears to be made up in the German, Greek, Hungarian, and Slav (particularly Russian) languages, the only substantial gap is in literature from China. For those interested, a concise survey of the literature and how it is drawn on, is available in the leading article (editorial) in Volume 16 (2) of the Abstracts (6).

Other services associated with the publication of Forestry Abstracts are: (a) The distribution of annual author, subject, species and geographical indexes for the items published in the journal.

(b) The publication in 3 out of 4 issues of the journal of an article objectively reviewing the complete literature on some particular subject of current interest and importance. Up to now these leaders have been written mainly in the United Kingdom, often by members of the Bureau staff. Suitable review articles originating in other Commonwealth countries would be most welcome; in this connection it is to be noted that the article appearing in the current number of Forestry Abstracts is the work of Canadian forest entomologists reviewing the subject "Forest Insect Control by Aircraft".

(c) The provision of a "centralized title service" by which reference cards of the current literature, fully classified and including the shorter abstracts, are made available to subscribers with a minimum of delay.

${ }^{1}$ A committee that was set up following the Ottawa Conference of 1932 to examine and report on the work of various Commonwealth agencies. 
In addition the Bureau has in the past issued separate publications (Technical Communications) on subjects of current interest that are beyond the scope of a leading article. These are prepared either by the Bureau staff or by individual specialists in the field in question.

Being an information centre, the Bureau is naturally equipped to answer enquiries and prepare bibliographies for those who require them in connection with research activities, the cost of these services, if any, being determinea by the time involved. While the preparation of translations is not a normal function of the Bureau, it has recently made arrangements to facilitate the interchange of translations of articles on forestry subjects between the different members of the Commonwealth.

As might be expected, the Bureau has affiliations with forestry groups in many countries and has co-operated with other organizations on projects of wide interest. It originated, and worked in close association with FAO and IUFRO in perfecting, a decimal classification for forestry literature known as the Oxford System (7), which now has international recognition, and it is at the present time co-operating with the Empire Forestry Association in the compilation of Part II of the British Commonwealth Forest Terminology. Also, the Bureau is the organizing centre for the FAO/IUFRO Joint Committee on Bibliography, which has been assigned responsibility for the preparation of multi-lingual forestry terminologies; in this connection the Bureau is at present co-operating with the Society of American Foresters in the compilation of a basic forest terminology in English preparatory to beginning work on the multi-lingual project.

To the research worker in forestry and allied fields and to those concerned with the application of such work, the services provided by the Commonwealth Forestry Bureau (and paid for in part by the Canadian Government) should be of vital concern. The question naturally arises-are these services being used as fully as they should be by Canadian foresters? Are, for example, the Abstracts reaching everyone they should? Anyone who is interested in having further information with regard to the activities of this organization should address their enquiries to the writer or to the Director of the Commonwealth Forestry Bureau, South Parks Road, Oxford, England.

\section{REFERENCES}

1. Commontealth Agricultural Burcaux. Annual Reports. Her Majesty's Stationery Office, London.

2. Commonwealth Agricultural Bureaux. 1954. Conspectus. Her Majesty's Stationery Office, London. pp. $47+$ append.

3. Forestry Abstracts Coverage List. 1953 FAO Forestry and Forest Praducts Studies No. 7, pp. 180. Food and Agricultural Organization of the United Nations, Rome.

4. GLASS, BENTLEY. 1955. A survey of Biological Abstracting. The A.I.B.S. Bulletin $\mathrm{V}$ (1 and 2), $(20-24$ and $18-21)$.

5. Guide to the Use of Forestry Abstracts, 1950. Commonwealth Forestry Burcau, Oxford, pp, 62. 6. The Literature of Forestry: an Appraisal. 1955. Forestry Abstracts 16 (2), (157-160).

7. The Oxford System of Decimal Classification for Forestry. 1954. Commonwealth Agricultural Bureaux, Farnham Royal, England. pp. 115. 